\title{
Physical, Epistemological and Metaphysical Perspectives on Quantum Theory: Constructed Experience?
}

\begin{abstract}
Zulena dos S. Silva
Pedro II College

This paper will present questions from three perspectives about Quantum Mechanics (QM): physics, epistemological, and metaphysical. The quantum phenomena do not fit with the parameters of classical physics, so a daily intuition on macroscopic world is dispensable when it is the quantum object investigated. This physical domain induces a new thinking, which requires also new concepts to describe such object. The QM is disturbing and stimulates epistemological reflections, as the issues of access about what is known; and metaphysical theme are not to be left behind with regard to QM: What would the quantum object to? What is apprehended when this object is perceived, once considered the disturbing characteristics that constitute its physical description: interference and non-separability? What is its nature? This paper focuses briefly on the analysis of B. d'Espagnat in Veiled Reality, which would represent the physical perspective of QT; for epistemological questions, one will resort to the Kantian conception of knowledge; and with regard to the metaphysical perspective, we will rely on an article by Professor J. B. Arenhart. It is necessary to note that the question that pervades in this paper is about if the experience in QM is built. Thus, we will try to seek clarity on the philosophical issues through QT, regarding the problems about the possibility of knowledge of the quantum object and its nature, and whether experience in this case is built. But furthermore, the QM instigates us to think whether metaphysics proceeds on the investigation of nature when it comes to the QM. And such a question is more than to have as problem as the scope of the description of physical data, but rather whether it makes sense or whether metaphysical research is pertinent to the QM.
\end{abstract}

Keywords: experience, knowledge, Quantum Theory, epistemology, metaphysics

\section{Introduction}

To thinking about the status of Quantum Theory (QT) or Quantum Mechanical (QM), how scientific theory - considered here in its earliest days, when developed by the Copenhagen School, how view of Niels Bohr-goes back to philosophical discussions about whether and how knowledge is possible and what is known. These classic philosophical questions are replaced, with regards to QT, three of their major problems are: (i) if there would be an epistemological limitation on the aim of QT and (ii) whether the QT would correspond to real objects or not, ${ }^{1}$ and yet (iii) about the nature of the data seized in the quantum domain.

Regarding the first problem about the QT, it is question whether the knowledge of the quantum data is feasible, since the measuring instrument interferes with it. In other words, the observation interacting with the

Zulena dos S. Silva, Dr. in History of Sciences and Techniques and Epistemology, from the Federal University of Rio de Janeiro (UFRJ) by HCTE Program, Teacher of the Pedro II College, Brazil; main research field: Philosophy, Epistemology, Theory of Knowledge, Philosophy of Science, Philosophy of Physics, and Metaphysics. 
observed leads us to ask if we can know what happens in the quantum state, since the interference seems to suggest lack of objectivity in describing the phenomenon. From this critical perspective, such interference would be revealing of the lack of a variable not yet known-it becomes necessary to be objectivity (detachment) in the description of the data to have knowledge of what happens in the quantum state. By this question, QT seems to be epistemologically limited. ${ }^{2}$ Since the observation interferes with the observed data, this leads to the second problem about the QT: if the data that happens, which is incompatible with the classical expectation of objective knowledge, corresponds to something real that presents itself altered, changed or if such entity (or process subject to interference in the quantum state) is unreal. In other words, the question is whether, in spite of its predictions and mathematical precision, the QT would be only an empirically adequate scientific theory and not correspond to physical data. This is the problem about the reality of what is known, about how to know that a data is actually apprehended once subjected to interference; it could actually be a mental or theatrical construct, but not really real, something external and in itself. ${ }^{3}$

These questions could be related to the following: if the experience of the quantum datum is constructed. Replacing the problem: if the interference of observation on the observed would be a construction of data that ultimately results from theories that shape the observation and if, therefore, there is no real thing to be referred to as quantum object.

We see in these problems exposed in items (i) and (ii) an emphasis on access to informed content. But as mentioned in item (iii), the third important problem concerning QT is about the nature of quantum object, and also about what its properties are. In this respect, we see an emphasis on the content informed, seeking to know about its substance, that is, what is the quantum object.

To deal with these questions in this paper, we will address QT issues through three approaches: the epistemological, the physical, and the metaphysical. We will consider the problem as to whether the epistemological and physical approaches can be dissociated, given the constituents of the quantum state as interference and non-separability, which allow doubt about the separation of these approaches in the quantum domain. This is considered due to the problem about a construction of the experience mentioned before and now linked to the QT. Related to this, we find the Kantian perspective of knowledge, and can inspect whether the association of QT with Kantian conception of knowledge is pertinent because it is understood as incomplete. So the real or unreal of quantum data is in the game.

But beyond those physical—interference and non-separability—and epistemological constituents—QT associated with the Kantian conception of knowledge-one must consider the ontological or metaphysical aspect, which concerns the nature of the quantum object. The metaphysical aspect arises insofar as the set of epistemological and physical questions about QT lead us to ask what the quantum object consists of. The Kantian framework opens space for the metaphysical approach, but this, in turn, can be developed by interesting formal problems concerning the individuality or non-individuality of quantum entities.

In order to examine the problems in the perspective of QT, briefly we will deal with the Kantian perspective for the epistemological aspect-based on his work Critique of Pure Reason (CPR), as well as with ideas of Bernard d'Espagnat in his work Veiled Reality for the physical aspect. And to deal with the metaphysical aspect related to QT, let's rely on the paper from Professor Jonas R. B. Arenhart, "The Received View on Quantum Non-individuality: Formal and Metaphysical Analysis.” Thus, the development of this text proceeds with the following sections: 2. The QT and the Kantian perspective of knowledge; 3. The interpretation on QT questions proposed by d'Espagnat; 4. About the metaphysical opening: identity and 
individuality of quantum object as explained in a paper by Professor Jonas R. B. Arenhart. And finally, in section 5, concluding with open questions, and the question of whether the QT experience built makes sense.

\section{The Quantum Theory and the Kantian Perspective of Knowledge}

The understanding that QT is incomplete, involving hidden variables to be clarified, may be associated with the understanding that it would be a physical theory tuned to Kantian perspective of knowledge-remembered here to open the problem about reality itself subject to knowledge, because we can only access it as it appears to us, a phenomenon according to the conditions of possibility of possible experience, which are a priori in the human mind, which can be seen in Kant's Critique of Pure Reason (CPR).

In this regard, we have: (a) the Kantian conception of knowledge indicates that empirical data are phenomena known from how they appear to the perception, according to a priori condition of possibility of knowledge, in the human mind, and that, therefore, things in themselves cannot be known; (b) since things in themselves would not be knowable, such theory of knowledge that admits this, falls into non-realism; (c) that the consideration of QT as incomplete consists in having such a theory as not dealing directly with reality, it being understood that there is no variable in QT that would allow the description of reality in itself, physical—if not in itself not it is physical, but imagined or constructed; (d) and therefore, interpreting QT as a case of Kant's theory of knowledge, it can be concluded that, since incomplete, it would not be realistic either.

Let us examine the following problem: Does associating QT with the Kantian perspective of knowledge imply non-realism?

One can answer this problem with a "no," because Kantian understanding does not mean a non-realism (a dogmatic idealist version ${ }^{4}$ ), but rather that reality as it appears to us is that it can be known-reality is not denied, only it is thought that in itself it cannot be apprehended. At this point, it is like affirming that reality itself is interfered with the measuring apparatus which is the human mind.

Nor does this imply that the sciences of nature, in Kant's perspective, are restrained by subjectivity, locked up by and in the human mind as if they could not be enlarged, moved on, advanced. It is worth remembering that in Analítica, in CPR, he calls attention to two types of deduction: the transcendental (which we can associate with the description of the human mind as a measuring device that interferes with reality, which, according to the interference of the human mind with its conditions of possibility of knowledge, apprehends it as a phenomenon, that is, as it appears to us) and the empirical one, concerning the sciences of nature.

In defining the transcendental deduction, Kant also establishes, by distinction, the definition of empirical deduction, as follows: “... the explanation of how these [concepts] can refer a priori to objects, and distinguish it from the empirical deduction that indicates the way a concept was acquired through experience and reflection on it, and so says respect not to legitimacy, but to the fact that possession arose” (CPR, Analytical Concepts, B118).

We see that a priori concept is of the understanding, the faculty of human reason, so to speak, that is an apparatus of measurement, which consists of our priori mode of knowing objects; as a condition of knowledge in the understanding - which organizes intuitions, which are immediate and particular apprehensions of something sensitive, empirical given - the transcendental concepts are considered as accessible by thought without support of experience, i.e., are not elucidated a posteriori.

It is important to be clear about the Kantian perspective of knowledge: Philosophy turns to a transcendental domain of discussion about the conditions of possibility of knowledge, where the justification of 
the possibility of knowledge itself is the question, in other words , the why or under what conditions knowledge is possible, the way of knowing objects is the objective of investigation; and as for the sciences of nature, such as physics, matter or physical phenomena matter, as well as demonstrate the "possession" of concepts in explanations about them, so these sciences are occupied with the empirical domain-as if by theoretical concepts were proposed.

In this way-and according to the formulation of "empirical deduction" proposed by Kant-the understanding of the critics to QT is unfounded, since all the sciences, even e.g., Classical Physics, are knowledge of phenomena, of objects that are such as they appear to the mental apparatus, that is, they are knowable according to the conditions of a priori possibility of knowledge, and this constitutes the reality or nature of empirical objects, being affected by mental or reason interference. In Kant, reason would be like the measuring apparatus of reality, interfering with it as a condition of possibility of knowledge of it.

But the doubts insist: are the sciences only deductive and in no way corresponding to reality (Considering that for Kant the natural sciences would be empirical deductions)? How would we know that they correspond to the facts, the natural data and are not merely speculations? Would Kant's theory of knowledge need not to dispense with the notion of thing itself? That is to say: by the understanding that Kantian theory consists of a description of a measuring apparatus that interferes with the reality of known objects, is not reality essentially so, without needing to suppose that there is a more fundamental and inapprehensible reality in itself?

Many issues exist and we will not deal with them here. Let us briefly see how Bernard d'Espagnat will think about the questions concerning QT.

\section{Bernard d'Espagnat's Interpretation of TQ's Problems}

It can be admitted that QT deals with reality and, therefore, is not an incomplete theory. The reality in the quantum dimension is thus how the data manifests itself through the interference of the measuring apparatus. At this point, we can rely on the notions of weak objectivity and non-separability thought by Bernard d'Espagnat in Veiled Reality.

Bernard d'Espagnat draws attention to the main puzzles about QM when one considers, in philosophical terms, the perspective of Realism. For him, these puzzles are weak objectivity and non-separability, which do not exist in classical physics. QM works with predictive rules; however, what is external reality in this domain presents considerable problems, since QM deals with unobservable entities. This leads to the question of whether the non-observable (QM) is real or conceptual expedients of an empirically adequate theory. And it should be noted that the use of predictive rules has (one) to be realized, to occur, with a margin of probability and precision - and this prediction, considering the problem of Realism, is articulated to the conception that a theory ultimately only counts for argumentative consistency, not because it corresponds to real, physical data.

The question that arises is whether we really need a reality. According to him, this question concerns the philosophical aspect of his investigation, and his answer will be affirmative- that is, yes, we need a reality. In turn, this positioning leads to the third question that he proposes: Is this reality intelligible? For him, physicists intend to describe things as they really are, but he understands that reality is unknowable or veiled - this position remembers the Kantian perspective of knowledge.

But in admitting this, he is led to think weak objectivity. All statements in physics are certainly objective, he says, but there are two types of objectivity: the strong and the weak. Strongly objective statements are those that a conventional realist can interpret (or interpret) as corresponding to a reality-both descriptive and 
external, which is independent of our existence or knowledge.

Models of QM are not strongly objective, according to B. d'Epagnat, that is, they are not independent of us, of our existence and knowledge. They refer basically to measures-and the greater notion of measurement is that it is not relative to who performs the operation of the measure, the process of observing and measuring. But for B. d'Espagnat, such statements need not be regarded as subjective, as long as they are valid for all—statements that are neither strongly objective nor merely subjective—carry weak objectivity.

Weak objectivity makes sense for QM, since the measure or record of the observed state is not wholly objective, but neither subjective nor strict sense, i.e., dependent on us or our knowledge, but that observation extends and merges with observed, to the point of interfering with it and constitute a variable thereof.

At that point, B. d'Espagnat turns to non-separability. As he notes, classical physics is built on the notion of analysis—not just mathematical analysis, but also conceptual, physical analysis: the view that physical systems can be conceived as composed of distinct parts and, since "laws of force" are knowledge, an exhaustive knowledge of these parts allows a complete knowledge of the whole.

In QM, it does not happen thus, the individual particles can no longer be assigned a wave function (nor, therefore, can be thought of as occupying any specific region of space), whereby the recording of the speed of a particle does not allow knowing about its locality—is distinguished from the notion of data analysis in which each of these has its status identified independently of the other, articulating in a whole.

In this respect, for B. d'Espagnat a problem must be remembered: What is actually measured? What is the observable and measurable quantum state itself?

In short, weak objectivity and non-separability are two basic characteristics of QM that do not fit our usual view, which therefore induces us to try to modify them. But it should be noted that, in fact, they are real enigmas only for those who take seriously the notion of "external reality" as a substratum of what appears. This exteriority in the sense of something beyond or in itself would not be presupposed in QT, rather reality happens in the quantum state of things itself. The variables, the occurrences, collapse on each other.

Faced with such observations, B. d'Espagnat points out that it seems hardly consistent to completely dispense with any notion of a logically prior reality in relation to knowledge-that is, in QT it is also necessary to consider something to be known, prior to its knowledge, and let us remember that in QT knowledge of something is a process in which the observation and the observed are "instantly" conjugated. To this he calls open realism; by this is meant: there is something, the existence of this does not come from the human mind. It is worth mentioning: 'Open realism. There is 'something' (is this 'something' the set of all the objects, that of all the atoms, that of all the events, God, the Platonic Ideas?- - this, at this stage, is not specified: one just says 'something') the existence of which does not proceed from the existence of human mind" (d'Espagnat 1995, 315).

It is worth noting that an idealist approach in the sense of Kant (CPR, Transcendental Idealism) does not claim that the existence of reality depends on the human mind—indeed, this is his criticism of Berkeley—but, and only, the knowledge of this reality depends on priori conditions that are mental. Of course, before Kant had already observed the problem of considering mental conditions as molds for the apprehension of external data, why to admit an external reality is a nervous end for the theorization of knowledge. ${ }^{5}$ But one can understand that the problem of access to reality, the possibility of knowing the external world is the crucial problem; and with it radical idealism is a thesis among others; can the problem be solved? It is enough for the realist to affirm a reality underlying the pretension of knowledge to deal with the philosophical problem of access to reality and 
the possibility of knowing something.

Going back to the point of the quotation from B. d'Espagnat, we find that, contrary to some conventional realists, he does not postulate anything concerning the nature of what exists, even if it is knowable; nor does it postulate that it is unknowable.

And as B. d'Espagnat acknowledges, the problem is left open: It must be decided on the basis of what factual knowledge, and in particular scientific knowledge, reveals.

Under such conditions, he says, it is difficult to find a name that is neutral enough for what exists, not to suggest characteristics or properties of it, which at this early stage of the investigation would be absurd to attribute to what exists. The least compromising, for him, is independent reality, not meaning that we cannot interfere with this reality, but that its existence is independent of our own. And according to him, about the activity of physicists, we can mention: "The conjecture that therefore seems the most reasonable is that the real business of physics is not to construct a scientifically well-established ontological theory, that this is probably quite an inaccessible goal, and that physics should be content to describe and synthesize the phenomena” (d’Espagnat 1995, 321).

\section{Metaphysical Openness: The Quantum Object as Non-individual}

We have seen here that for Bernard d'Espagnat Physics as science proceeds by description of the physical object (phenomenon or state of things); in turn, Philosophy would deal with the nature of the object, dedicating itself to the ontology. And for Kant, the phenomenon (the reality described by Physics) is as it appears to us; then the human mind-encompassing the conditions of possibility of experience-is an apparatus of measurement, since the possible experience is that of the phenomenon, that is, of the empirical data as it appears to us-in this we find a connection between TQ and the Kantian conception of knowledge. And it is worth remembering that according to Kant, Physics proceeds by empirical deduction and Philosophy (Critical) by transcendental deduction (see about this in section 2 of this paper). Thus, we have an epistemology: an analysis of knowledge as to what it consists and its reach or limit.

But beyond the physical and epistemological approach to which we have dedicated ourselves before, we now turn to the ontological or metaphysical aspect that can be linked to QT. Metaphysical questions, for Kant, go beyond the epistemological domain - concerning the analysis of the conditions of possibility of knowledge, as transcendental deduction - and that of the possible experience, that is, of the physical world such as phenomenon; but for him such questions would not be illegitimate, rather rational.

And regarding the quantum object, the openness to Metaphysics can be seen in the perspective of reflections on identity and individuality, and to expose them we will base ourselves on an article by Professor Jonas R. B. Arenhart, “The Received View on Quantum Non-individuality: Formal and Metaphysical Analysis.” Thus, metaphysics, as a tendency of rationality, is now not restricted to questions such as immortality of the soul or possibility of freedom. In other words, the possibility of metaphysics would not be limited to concerns about whether life is reduced to materiality, or whether there is something vital beyond what is perceived as physical, concrete — or even if the world remains in spite of our death—as well as whether our existence exceeds the finitude of the body, with non-corporeal life, if something of immaterial life endures beyond biological deterioration; or concerns about whether our will and actions can perpetrate on their own a series of events regardless of external causes, inclinations, external factors such as social and historical values, or internal as psychological or organic constraints—or in other words, if there are principles for the actions that do 
not order the nature.

The intensification of metaphysical discussion, as in the case of quantum objects, stems from logical questions and revision of the concept of identity: individuality or, more precisely, non-individuality interconnects with the logical question about the possibility of dispensing identity in the case of entities quantum mechanics. We have seen that interference and non-separability disrupt the ordinary understanding of objective description of objects, of objective observation of data. But beyond those aspects that reach the notion of knowledge of physical data, the notion of the nature of the object perceived or considered as given is what can also be thought. The problem of access to reality, so to speak, is epistemological, but as to what is what is accessed, or more precisely, what allows affirming something as something is ontological or metaphysical—and the description of processes of physical manifestation in the sciences of nature does not enter into this domain of discussion.

Now the notion of individuality and identity being thought in the realm of beings, as to the condition of thinking something as something, of thinking what is individual, is an investigation of the metaphysical order. Let us see how this follows with the ideas of Arenhart.

J. R. B. Arenhart observes that the received view (RV)—proposed by the pioneering QM scholars, focused on questions about the nature of the quantum phenomenon—advocated non-quantum individuality and this condition of non-individuality implying loss of identity. With this, the quantum object is regarded as something without identity. In his article, the author observes that the current literature on the subject associates RV with non-reflexive logical systems (NR); but for Arenhart, such an association is not necessary. According to him, $\mathrm{RV}$ can be thought independently of the NR system and thus preserve alternatives to think non-individuality. Here, we will not deal with the whole proposal developed by the author on this subject, but we will stick to the debate about individuality insofar as it dispenses with identity, and this as a metaphysical problem.

The discussion of non-individuality indicates that identity would be rethought, which, in turn, demonstrates a review of our everyday understanding that presupposes that in referring to something there is an underlying or substantial referred to, which bears identity; or as a common or truistic understanding that this something to which we refer is identical with itself, considering this self as the substantial, the thing itself and not another. However, the understanding of what is a quantum datum escapes this familiar understanding of what one understands when one understands what something is.

A first point to mention is that to the extent that the notion of individuality refers to quantum entities, the interconnection of notions such as identity and indiscernibility to individuality will be discussed: those notions are controversial to demarcate an individual: how to identify something in its particularity in a state of things in which similar ones are manifested and the distinction of something gets troubled, since it is debatable to know if something that presents itself is the same or if it is another, distinct numerically, although similar. The relationship established between individual, identity, discernibility, is stirred when in the light of the problems related to the access and apprehension of quantum data. Thus, we see that individuality in connection with the notion of identity finds in indiscernibility something that affects the state of affairs of identification of the object as to whether it is the same or the like. That is, there is difficulty in identifying or individualizing due to similarity or equality between entities. As seen, one cannot discern something, with which its identification is compromised.

But J. R. B. Arenhart calls attention to another metaphysical approach that allows us to think of identity dissociated from discernibility, since two individuals can share properties, that is, they are similar. This other 
approach lies in the understanding of Transcendental Individuality (TI) principles, which would be those that attribute individuals to individuality as something beyond their properties. In this way, we can understand that individualization would be for identification, and in turn distinguish from discern. And with this, the previous problem is separated because one can identify individuals who share properties, which do not allow distinguishing them, or that make them indiscernibles, problem mentioned before.

It is observed by J. R. B. Arenhart that the case of non-individuals, those who lack identity-as interpreted by RV on quantum data-does not seem to involve TI. If they do not bring transcendent identifying properties they are devoid of identity and also indiscernible. Here we cite:

(...) non-individuals, according to TI principles, are the entities not bearing a transcendental individuality, and their formal representation is achieved in non-reflexive systems of logic. On the other hand, those items may also be indiscernible without being identical (given that identity does not apply), so an alternative metaphysics in which PII [Principle of Identity of Indiscernibles] is violated is also available. (Arenhart, 1330)

It could be considered that not behaving transcendental individuality the non-individuals would be neither metaphysical; but J. R. B. Arenhart points out that no individuals do not imply denial of identity—so that if TI is for identity, denial of it would correspond to the denial of TI, which requires individuality in individuals beyond properties which therefore have metaphysical individuality and identity was denied, the metaphysical aspect with TI would be as well. But according to J. R. B. Arenhart no individuals can be admitted with being having another domain of application other than that in which are the individuals, which would have identity. And this other domain can also be metaphysical. Identity involves a scope of application distinct from that of non-individuals. It is worth:

Notice that once individuality is framed in terms of TI principles, it gets a linguistic representation in terms of the reflexive law of identity, and consequently, in every system where this law holds universally there are only individuals. Furthermore, it is impossible to deny this law by using negation; one must understand the failure/restriction of the law of identity as a kind of "reduction of the scope of application" rather than strict violation through denial. Notice also that this hoice of the relation between identity and TI makes it virtually impossible to keep identity in a language and use it to deal with non-individuals. (Arenhart, 1330)

The author wonders whether this very understanding about the restricted application of identity would also be restricted, flawed, since we need the notion of identity. But considering that the question grants the benefit of the doubt to the defense of identity, an alternative interpretation will be found to the dilemma with which the author deals and is the motivator in his writing, namely: On the one hand, identity seems very important to be discarded; on the other hand, the RV seems to require that identity be dispensed with.

J. R. B. Arenthart points out that perhaps what fails is a particular interpretation of RV related to a particular formal system, and as he himself asks: "Can't we think about alternative metaphysical renderings of non-individuals? Of course we can (...)” (1340).

He underscores the possibility of alternative approaches to metaphysical understanding of non-individuals, and that such approaches would not have relations with strong metaphysical interpretations regarding identity.

And J. R. B. Arenhart notes that:

... one must acknowledge that the particular objects of a given scientific theory may be classified as individuals or as non-individuals, so that a failure of the application of some previously chosen principle of individuality does not always count against the validity of that same principle, but may be seen as attesting to the fact that we are facing a non-individual. (1340) 
Here we will not consider what specific alternatives are. But by observing that alternative approaches to metaphysics may exist for individuals rather than individuals, or that such for non-individuals while dissociated from metaphysical interpretations of identity, it leads us to questions such as: Which approach(es) or perspective(s) would be the most appropriate for the metaphysical understanding of non-individuals? Or, could we admit some of them as the truest one(s)? Are there distinct metaphysics for data distinct from reality? Different realities, distinct beings, different metaphysics? Why not? Or, what would be impeding it?

The conduct of Arenhart showing the possibility of thinking the metaphysics of non-individuals-although the bias of individuality has its place-in the background emphasizes how much in metaphysical terms the QM is instigating.

\section{Conclusion}

By means of the one developed up to here, it is necessary to emphasize the differences between Kant and B. d'Espagnat with respect to what can be understood by possible knowledge.

In the first place, we can remember that for Kant valid knowledge must be universal and necessary (CPR, Introduction, B) — that is, experience organized by concepts—and for B. d'Espagnat enough that physics turns to phenomena as a singular manifestation, that is all that can be observed-and the universal, objective character is exposed via the mathematics that describes it.

Second, with respect to the presupposition of the thing in itself, for Kant it is noumenon that is noted in its theory of knowledge, and this is because Kant recognizes and faces the Scandal of Philosophy (CPR, Preface, $\mathrm{XL}$, note 12, Issue B): One thing would be to say that reality as we perceive it does not exist and therefore cannot be known; another is to say that being known as we can, does not imply that it does not exist, it exists in itself, as noumenon, but knowable according to the priori conditions of possibility in us, and such conditions are objective; in turn, for B. d'Espagnat the thing in itself would be outside the field of investigation of the physicists. And let us remember that for Kant, human reason in dedicating itself to noumenon, extrapolates the possible experience, but this would not be a defect, but a characteristic of it.

The presupposition of reality itself may be not an epistemological question about competing and explanatory scientific theories of ulterior reality, but rather a problem of reason that extrapolates the conditions of possibility of possible experience - which in the last analysis is singular, by weak objectivity—and so the reason arrives to the metaphysical domain, according to Kant.

And in the case of QT, what would correspond to the in itself, that which goes beyond the measure, that which "escapes" from observation-according to classical parameters-would be something presupposed? Would not this be an indication that something in itself or noumenon still here makes sense and manifests itself through interference, whose process is what can be apprehended? B. d'Espagnat admits that such an object of speculation is not for the investigation of physicists, and in that respect to what Kant understood as possible knowledge: This is about what is as it appears to us, and what escapes would be object of speculation of reason.

From the previous reflections, it is necessary to question whether the experience in QM is built. To deal with it now, consider the following directions:

(a) On the one hand, if one wants to understand constructed experience as unrealistic, QM would not be constructed, by the vision of B. d'Espagnat: The observed physical data is private, grasped in its uniqueness, and for him there is a reality observed in the quantum domain and it would not be up to physicists to investigate some substrate of experience beyond the changed, collapsed phenomenon. 
(b) On the other hand, to understand the interaction between observation and observed as a composition from which the quantum phenomenon results in its particularity, may also suggest that the experience of the quantum phenomenon is constructed according to the interference.

Once the one in item $a$ has already been developed in this text (see section 2), let's keep item b in view of the question of whether or not the experience in QT is built.

Then, considering item $b$, there would be no reality beyond the content of the observed, recorded information, being real what manifests itself by interference or the quantum object considered unreal because it is counterintuitive. So experience would be either something real out of the classical molds, or something unreal because it was outside the classical molds—-though it sounds strange to speak of unreal or unobservable experience.

The problem that we have in the psychophysical parallelism in this case is to know which end weighs in the line that demarcates the quantum object in relation to the process of interference in the knowledge or apprehension of the object: in the case of QM the identification of what happens is referred to object or the process of seizing it? That seems to be the bottom line.

Weighing to the side of knowledge, observation, and the measurement process of quantum data, one may suggest that the object is unreal, in the sense that, by theoretical limitation, reality has not yet been properly known, an epistemological limitation of theory does not allow describing or recording what occurs.

And weighing to the side of the object, the latter being susceptible to interference, there would be no limitation of the theory, but recognition that its reality is counterintuitive, that it is unreal in the sense of not conforming to the standard classical (object removed from observation)— the object of experience of the quantum domain consisting of a fusion with observation —is not understood here as a theoretical limitation.

The question of how to know that a theory corresponds to reality in the classical molds-the problem of truth as correspondence-seems no longer to fit, since the process in which the (non-real, counterintuitive) object collapses with observation consumes this separation. Now the question becomes what is experience in this state of things.

But why experience would be the theme? Why is the quantum data implied as experienced? One tends to understand experience as a direct apprehension of something in its uniqueness, and that thought apprehends something indirectly and by what it confers as general, conceptual. But could not the quantum die be shaped by a theoretical understanding that it merges with observation? What is the reality of this state of things? Is there anything else to say or know about the quantum datum, other than the realization that observation interferes with the observed?

What we have now is a problem about demarcation of what the quantum object would be and what the conceptual would be that goes beyond it, the range of ideas attributed to it, but which could not be its properties, and which would thus promote deviations in the investigation of nature-concern demonstrated by Hume in his critique of the notion of causality. ${ }^{6}$ So, what is known when the quantum object is known?

As an unfolding of this last question, we find the metaphysical openness about the nature of quantum entities, which in turn can be shown as non-individual, as we have seen from the perspective of J. R. B. Arenhart. And now we are still to be faced with the definition or formulation of the properties of non-individuals or whether it would be appropriate to think about properties of non-individuals, or even if pertinent something without properties. But we can remember that, as a physical data, a quantum object presents itself by interference and non-separability—-these physical constituents and epistemological conditions. 
But for the quantum object in the metaphysical perspective how cannot such individuals be defined, understood? In short, what would non-individuals be in metaphysical terms?

This last question brings us back to the substance of this paper, whether or not experience is built. Are not individuals constructed with metaphysical appeal, but without substantiality? That is, would not individuals as metaphysical notions correspond to quantum entities or would they be mere interpretations, but not corresponding to physical data? Do they only make sense in possible, plausible theoretical approaches?

A final point to be considered here is whether the question as to whether experience is a construct or not, once considered the Kantian perspective of the possibility of knowledge, is to be possible as it appears to us. The Kantian proposal seems to merge construction with what is independent of construction: Reality itself would be captured by mental conditioning, and these would construct the knowledge of experience. The Kantian's perspective is as that dispenses with the problem of radical idealism and that of integral (or naive) realism, and thus the question of whether or not the experience is constructed falls outside this categorical framework. Or is the Kantian criticism insufficient in the face of the Scandal of Philosophy which it itself recognizes and assumes to think?

But it is curious that the metaphysical tendency, which for Kant extrapolates the possible experience, finds source in a science in force in the present day, Quantum Mechanics. Just as Newton's Physics suggested Kant's thought in his day, the QM proves to be instigated either by the physical aspect, or by the epistemological and also by the metaphysical, as seen in J. R. B. Arenhart's paper on the possibility of metaphysics by the conception of non-individuals.

\section{Notes}

1. About these problems, it is worth mentioning W. Pauli in his article "Matter" in Writings on Physics and Philosophy: “[...] the possible sources of information about the object are irrevocably altered by observations. The existence of such alterations reveals a new kind of wholeness in nature, unknown in classical physics, inasmuch as an attempt to subdivide the phenomenon defined by the whole experimental arrangement used for its observation creates an entirely new phenomenon” (Pauli 1994, 33). And by the way, let us look at N. Bohr's observation in his paper of 1938, "The Causality Problem in Atomic Physics," about the proposition by Einstein of an experiment that captures the objective state of the observed and thus an observation also aims to be consequently feasible: "[...] the example of a typical experimental arrangement, suggested by Einstein and discussed at a meeting of the Solvay Council of Physics in 1930. In this arrangement, the exchange of energy during a contact between an atomic object and a measuring body is determined by the difference in weight of this body before and after the contact. At first sight it might appear that the weighing of the body could be performed without hindering the accurate control of the time at which the contact takes place, as recorded by a clock rigidly connected with the body concerned. Obviously, however, this would furnish information about energy and time variables to the object with greater accuracy than is compatible with quantum mechanics and on closer examination, it is also seen that the use of any weighing device with a given accuracy will exclude such a control of the time of contact. In fact, the necessary latitude in our knowledge of the position of the body in the gravitational field will imply an uncertainty in the regulation of the clock, connected with the assigned accuracy of the energy measurement just by the quantum mechanical uncertainty relation. This result was of course to be expected, in view of the way in which the equivalence arguments of general relativity are based on purely kinematical and dynamical principles rationally incorporated in quantum mechanics. The main lesson of the whole discussion is rather to enforce again the necessity of describing entirely on classical lines all ultimate measuring instruments which defines the external conditions of the phenomenon, and therefore of keeping them outside the system of the treatment of which the quantum of action is to be taken essentially into account” (Bohr 1938, 106-7). Through what Bohr says in this text, on the interaction between observed and observation by the measuring apparatus, it can be understood that the quantum data reduction does not indicate in epistemological limitation; the observed quantum object manifests itself as collapsed, and this does not fail to record the data by the measuring apparatus, there is no hidden variable to be interpreted yet, since what happens in the quantum state is revealed as such by interference. The text "The Causality Problem in Atomic Physics" can be found in The Philosophical Writings of Niels Bohr, Volume IV: Causality and Complementarity. 
2. The question about QT that seems to be epistemologically limited could be exposed with the following questions: Is QT an incomplete theory or not? How to understand the scientificity of QT? In this regard, give criticism to QT by Einstein, Podolski and Rosen in the famous article "EPR," 1935, in which the question proposed is: "Then either (1) the description of reality given by the wave function in quantum mechanics is not complete or (2) these two quantities cannot have simultaneous reality. Consideration of the problem of making predictions concerning a system on the basis of measurements made on another system that had previously interacted with it leads to the result that if (1) is false then (2) is also false. One is thus led to conclude that the description of reality as given by a wave function is not complete” (“EPR,” 1935, 777). And about the Einstein's interpretation of QT, it is worth mentioning the exposition by Nelson Pinto Neto, Member of the Brazilian Center for Physical Research (CBPF), in his book Teorias e Interpretações da Mecânica Quântica, Chapter 4, "Emaranhamento, não localidade e contextualidade": "The way that Bohr found to accommodate classical concepts with strange quantum phenomena was complementarity, with which he clung to the end. For him, there was nothing beyond this fundamental notion. For Einstein, who considered it to be one of the primary goals of science to refine the models in such a way as to make them increasingly independent of observers, as happened in general relativity, there would be no problem in abandoning classical notions as long as the new concepts to be introduced open new avenues of understanding and experimentation, and promote a progressive refinement toward an absolutely objective description of the material world" [emphasis added] (34-35). Also it is worth mentioning the Popper's conception of MQ in "Realism in Quantum Mechanics and a New Version of the EPR Experiment," in which he understands that the Copenhagen's view on QM proposes a theory about our knowledge of particles; but Popper opposes the conception of Copenhagen and states: "the particles themselves possess Sharp positions and, at the same time, Sharp momenta" (5). And let's look at his statement about the EPR and Copenhagen interpretation: "I propose that the thesis which EPR tried to establish was this: a particle possesses sharp position and momentum, and thus a trajectory; and our knowledge of a particle's position cannot, qua knowledge, disturb its momentum: the particle's momentum remains undisturbed. It remains a particle, having position and momentum and a trajectory, a path. But the Copenhagen interpretation wishes us to accept that our knowledge of the position B (obtained y measuring A) must, merely as knowledge, make the momentum of B 'indeterminate,' since no particle can have both. But if this is so, then our knowledge would make the momenta on the left scatter, upon repetition (even with the screen on the left removed). This was the EPR argument as I see it, and I wish to apply it to my experiment. On the other hand, according to the Copenhagen interpretation (and also according to Bohr, if I understand him), we are presented with the following paradox: If we obtain knowledge of the position on the right, then this knowledge should disturb, or make indeterminate, the momentum of the particle on the left. And this would make the momenta on the left scatter upon repetition. This is an inescapable consequence of the Copenhagen interpretation; and it is implicit in Bohr's three replies to EPR (4). But it has not, I think, been stated before explicitly (except that it was alluded to by myself (5)). I believe that Einstein wanted to say, essentially, that our knowledge has no physical consequences - it cannot disturb the momentum of a distant particle (of course, a screen would disturb the momentum)" (Popper, 8) [griffin of the author].

3. Is the QT merely consistent, but without corresponding to some physical truth? Is it just a theory that reveals the instrumentalist (i.e., serving, but not true) content of the natural sciences? These problems lie at the heart of the debate between realistic views and those who argue that a scientific theory is empirically adequate and not corresponding (even roughly) to the truth of the facts. In the thread of discussion of this theme, it is worth checking the paper of Tiago L. T. de Oliveira, "Algumas razões para levar a sério a metaindução pessimista.” Principia 18 (2): 269-90 (2014).

4. Critique of Pure Reason, Transcendental Aesthetics and the Second Book: Analytic Principles, B 275. Kant's argument for rebutting Berkeley would be: If the external world is intuited by a priori forms of Sensitivity, conditions of possibility of its apprehension, we perceive phenomena, that is, how things appear to us, even though we cannot perceive them in themselves.

5. This question is known from Kant as the Scandal of Philosophy; on the Scandal of Philosophy, see Critique of Pure Reason, Preface, XL, note 12, edition B. We quote here a passage: “(...) permanece contudo um escândalo da Filosofia e da razão humana geral ter que admitir a existência das coisas fora de nós (das quais recebemos todo o material dos conhecimentos mesmo para o nosso sentido interno) com base apenas na fé e, ao ocorrer a alguém colocar essa existência em dúvida, não lhe poder contrapor nenhuma prova satisfatória” (Kant, $C R P$, Prefácio, XL). It is worth mentioning the paper of Professor Roberto H. Sá Pereira, Member of the Department of Philosophy of the Federal University of Rio de Janeiro (UFRJ), "What Is the Scandal of Philosophy?" in which the central question is on the Kant's prove with his Refutation of Idealism, in the others words, it is what is the scandal of philosophy. The author, considering a distinction between metaphysical external-world skepticism and epistemological external-world skepticism, proposes that the problem is that thing exists in itself as a substantia noumenon, not the existence of thing outside of us, in the sense of the problem epistemological.

6. About this Hume's perspective concerning of the causality to be or not to be real, but resulting of habit, can be seen as analogous to the question of what the quantum object would be, about what is known when the quantum object is observed, what is it: individual or non-individual. In paper by Professor J. B. Arenhart, the perspective is that it is non-individual can to be thought; and so, I understand that the question is analogous, but the answers are different: Hume does not proposes to think the nature of non-causality, only to recognize that causality is not a phenomenon of nature, nor an idea of reason; and Professor J. R. B. Arenhart argues that non-individuals can be thought of, i.e., that individuals can be conceived or exist, but non-individuals could also be conceived - and thus would consist of the nature of the quantum object (and why not?). In relation to Hume's critical analysis of the idea of causality, see his Inquiry... (Investigação sobre o entendimento humano, in Portuguese). 


\section{Works Cited}

Arenhart, Jonas Rafael Becker. “The Received View on Quantum Non-individuality: Formal and Metaphysical Analysis.” Synthese 194.4 (2017): 1323-47.

Bohr, Niels. "The Causality Problem in Atomic Phsics.” The Philosophical Writings of Niels Bohr. Volume IV: Causality and Complementarity. Eds. Jan Faye and Henry J. Folse. Woodbridge, Connecticut: Ox Bown Press, 1998. 94-121.

D’Espagnat, Bernard. “Open Realism.” Veiled Reality: An Analysis of Present Day Quantum Mechanical Concepts. New York: Adisson-Wesley, Publishing Company, 1995. 309-59.

Einstein, A. et al. “Can Quantum-Mechanical Description of Physical Reality Be Considered Complete?” Physical Review, Vol. 47. Princeton, New Jersey: Institute for Advanced Study, 1935. 777-80.

Moosburger, Udo Baldur and Rohden, Valério, trans. “Os Pensadores.” Crítica da razão pura (in Portuguese). Por Kant, Imannuel. Col. São Paulo: Ed. Abril, 1983.

Neto, Nelson Pinto. "Emaranhamento, não localidade e contextualidade.” Teorias e Interpretações da Mecânica Quântica (in Portuguese). CBPF/Livraria da Física. 33-52.

Oliveira, Tiago Luis Teixeira de. “Algumas razões para levar a sério a metaindução pessimista.” Principia, 18.2 (2014): 269-90. Published by NEL_Epistemology and Logic Research Group/Federal University of Santa Catarina (UFSC), Brazil.

Pereira, Roberto Horácio Sá. “What Is the Scandal of Philosophy?” Academia.edu 26 (2017): 1-31. $<$ http://www.academia.edu/34030977/What-is-the-Scandal-of-Philosoph-Forthoming-in-the-International-journal-of-Skeptici $\mathrm{sm}>$.

Popper, Karl. "Realism in Quantum Mechanics and a New Version of the EPR Experiment.” Open Questions in Quantum Physics. Eds. G. Tarozzi and A. van der Merwe. 1985. 3-25.

Ribeiro, Vera, trans. Física atômica e conhecimento humano (in Portuguese). Por Bohr, Niels. Contraponto, Rio de Janeiro, 1995.

Schlapp, Robert, trans. "Matter." Writings on Physics and Philosophy. By Pauli, Wolfgang. Eds. Charles P. Enz and Karl von Meyenn. Berlin: Springer-Verlag, 1994. 27-34.

Valandro, Leonel, trans. “Os Pensadores.” Investigação sobre o entendimento humano (in Portuguese). Por Hume, David. Col. São Paulo: Ed. Abril, 1973. 129-61. Seções I-VII. $1^{\text {a }}$ edição. 